\title{
Formulation and Evaluation of Erodible Ocular Films of Valacyclovir Hydrochloride
}

\author{
K. R. Naga Priya ${ }^{1}$, Sayani Bhattacharyya ${ }^{1}$ and Ramesh Babu, P.
}

Department of Pharmaceutics, The Oxford College of Pharmacy, Bangalore, India

Received: November 19, 2013; Accepted: March 02, 2014; Published (web): June 29, 2014

\begin{abstract}
The present work focuses on formulation of erodible ocular films of valacyclovir hydrochloride (VH) for the treatment of ocular herpes to enhance therapeutic effect through prolonging contact time with the corneal surface. Nine films were prepared by solvent casting method using different ratios of polymers HPMC E 15 LV and PVP. The FT-IR studies showed no interaction between drug and the polymers. Developed formulations were evaluated for tensile strength, \% elongation at break, strain, folding endurance, uniformity of thickness, weight variation, \% moisture absorption, surface $\mathrm{pH}$, drug content, in vitro release, kinetics study, sterility test and eye irritancy test on Rabbit eye. On the basis of these evaluations it was found that with increase in hydrophilic polymer content the mechanical properties and release rate of the films were improved. The kinetic study revealed case II transport. The eye irritancy test showed that the films were free from ocular toxicity and irritancy.
\end{abstract}

Key words: Ocular film, valacyclovir hydrochloride, HPMC E 15 LV, PVP, propylene glycol, in vitro drug release

\section{INTRODUCTION}

Ophthalmic inserts are defined as sterile preparations, with a solid or a semi solid consistency, whose size and shape are especially designed for ophthalmic application. They are essentially composed of a polymeric support containing drugs, the latter being incorporated as dispersion or a solution in the polymeric support ${ }^{1}$. These soluble inserts offer the advantage of being entirely soluble so that they do not need to be removed from their site of application, thus limiting the intervention to insertion only ${ }^{2}$.

The objective of this study is to formulate a small, pliable flat disk, oval or round in shape with a desired thickness for the treatment of ocular herpes to provide a localized control. The main purpose of preparing ocular inserts is to increase ocular bioavailability by increasing the corneal contact time. Fewer administrations provide patient compliance.

Eye Herpes is a common and recurrent viral infection affecting eyes. It is caused by Herpes simplex virus which is easily transmittable through the contact with an infected patient suffering from this disease.

Correspondence to: Sayani Bhattacharyya

Phone: +447404237669 .

E-mail: sayanibh@hotmail.com

Dhaka Univ. J. Pharm. Sci. 13(1): 75-81, 2014 (June)
Valacyclovir hydrochloride is an antiviral drug effective in the treatment of ocular herpes, generally given orally in high doses. Research has shown that ocular penetration of the prodrug Valacyclovir was much better than acyclovir in rabbit eye by carrier mediated transport mechanism. ${ }^{3,4}$ So an attempt has been made in the present work to make an ocular film with the polymers HPMC E $15 \mathrm{LV}$ and PVP. The polymers used are water soluble and show no interaction with the drug. Ocular films of Valacyclovir hydrochloride were prepared by solvent casting method.

\section{MATERIALS AND METHODS}

Valacyclovir hydrochloride (VH) was received as a gift sample from CIPLA Private Limited, Mumbai. HPMC E $15 \mathrm{LV}$ and PVP were obtained from S.D. Fine Chemicals Mumbai. All other reagents and solvent used were of analytical grade.

Preparation of ocular inserts. ${ }^{5,6}$ The ocular films of Valacyclovir hydrochloride were prepared by solvent casting method. Weighed quantity of polymer HPMC E $15 \mathrm{LV}$ was dissolved in distilled water under continuous stirring as per the quantity mentioned in Table 1. Required amount of Valacyclovir hydrochloride was added to the 
polymeric solution. The medicated polymer solution was sonicated for fifteen minutes to remove air bubbles followed by the addition of plasticizer Propylene glycol. The resultant solution was stirred. After proper dispersion and weight adjustment, the casting solution was poured on glycerine coated Petri plate which was covered with an inverted funnel to allow slow and uniform evaporation of solvent at $40^{\circ} \mathrm{C}$ for $24 \mathrm{~h}$. The dried film thus obtained was punched with sharp edged die into 10 pieces.

Table 1. Composition of ocular films of valacyclovir hydrochloride.

\begin{tabular}{lccccccccc}
\hline Formula & F1 & F2 & F3 & F4 & F5 & F6 & F7 & F8 & F9 \\
\hline Drug & 300 & 300 & 300 & 300 & 300 & 300 & 300 & 300 & 300 \\
PVP(mg) & - & 400 & - & 600 & 500 & 500 & 400 & - & 400 \\
HPMC(mg) & 500 & 600 & 600 & 500 & 500 & 600 & 500 & 400 & 400 \\
Propylene glycol(ml) & 3 & 3 & 3 & 3 & 3 & 3 & 3 & 3 & 3 \\
Water q.s 10 gm & Q.S & Q.S & Q.S & Q.S & Q.S & Q.S & Q.S & Q.S & Q.S \\
\hline
\end{tabular}

\section{Evaluation of ocular films, mechanical properties} and tensile strength ${ }^{7}$

The tensile strength of the ocular films was measured using a tensile strength instrument where one end of the film was attached with an adhesive tape and the other end of the film was fixed by adhesive tapes with a small pin placed in between the base plate and film to keep the film straight while stretching. In the adhesive tape a small hole was made near the pin in which a hook was inserted. The hook was attached with a thread, passed over the pulley where a small pan was attached to hold the weights. A small pointer was attached to the thread, which travelled over the graph paper affixed on the base plate. To determine the tensile strength, weights were gradually added to the pan to increase the pulling force until the patch broke. The distance travelled by the pointer on the graph paper before the breaking of the patch determined the elongation. The weight required to break the patch was noted as break Load. Tensile strength was calculated using the following formula:

Tensile strength $=\frac{\text { Breaking Load }(\mathrm{N})}{\text { Cross sectional area of the sample }}$

\% Elongation at break. Percentage elongation at break was calculated according to the following formula.

$$
\% \text { Elongation }=\frac{\text { Change in lenght }(\mathrm{mm})}{\text { Original length }(\mathrm{mm})} \times 100
$$

Strain. Strain was calculated according to the following formula.

Strain $=\frac{\text { Change in lenght of the ocular film(mm) }}{\text { Original length of the ocular film (mm) }}$

Folding endurance. ${ }^{8}$ Folding endurance for ocular inserts were calculated by folding the films repeatedly in the same position till a crack appeared. Number of folds required to produce the crack were counted. Folding endurance test was repeated using more sets of ocular films.

Uniformity of thickness. ${ }^{9}$ The thickness of the insert was determined using Micrometer gauze (Mitotoyo, Japan) at five different points of each insert. The mean value was calculated for each formulation.

Weight of ocular film. ${ }^{10}$ The ocular film was taken out and weighed using digital balance and the average weight of each insert was determined.

$\%$ Moisture absorption. ${ }^{10}$ The percentage moisture absorption test was carried out to check physical stability or integrity of the film at humid condition. The films were initially placed in desiccators containing silica gel for one day to ensure no moisture was absorbed by the films. The films were weighed individually. Then the films were placed in desiccators containing saturated solution of sodium chloride and $75 \pm 5 \% \mathrm{RH}$ was maintained. Each day the films were taken out to weigh individually. The \% moisture absorption was calculated using the following formula. 
\% Moisture absorption $=\frac{\text { (Final woight }- \text { Intial weight })}{\text { Initial weight of the film }} \times 100$

Surface $\mathbf{p H} .^{10}$ Surface $\mathrm{pH}$ test were carried out to investigate any possible eye irritation. For this test the inserts were allowed to swell in a closed Petri plate at room temperature for 30 minutes in $0.1 \mathrm{ml}$ of double distilled water. The insert was removed and placed under digital $\mathrm{pH}$ meter to determine the surface $\mathrm{pH}$.

Drug content uniformity. ${ }^{11}$ To check the uniformity of the drug in the circular films, this test was carried out by using five inserts from each batch of film. Each insert was placed in a glass vial containing $5 \mathrm{ml}$ of phosphate buffer $\mathrm{pH} \mathrm{7.4}$. The inserts were dissolved by the aid of a magnetic stirrer; the solution was then filtered through filter membrane. $1 \mathrm{ml}$ from the filtrate was withdrawn and assayed spectrophotometrically after suitable dilution at $255 \mathrm{~nm}$ against a blank solution which was prepared by using a placebo film in the same solvent to prevent the interference of polymer and plasticizer.

Drug-polymer interaction. Infrared (IR) spectroscopy (using IR spectrophotometer FTIR8300, Shimadzu [Kyoto, Japan], by the $\mathrm{KBr}$ pellet method) was performed on Valacyclovir Hydrochloride and pure polymers. Then polymer containing Valacyclovir Hydrochloride was subjected for investigation to determine the compatibility between drug and various polymers used.

In vitro drug release studies. The in vitro drug release studies were carried out using diffusion cell. The insert was placed on the cellophane membrane and isotonic phosphate buffer $\mathrm{pH} 7.4$ was added to it. The entire surface of the membrane was in contact with the receptor compartment containing isotonic phosphate buffer $\mathrm{pH} \mathrm{7.4.} \mathrm{The} \mathrm{content} \mathrm{of} \mathrm{the} \mathrm{receptor}$ compartment was stirred continuously using magnetic stirrer and its temperature was maintained at $37^{\circ} \mathrm{C} \pm 0.5^{\circ} \mathrm{C}$ at $50 \mathrm{rpm} .1 \mathrm{ml}$ of the solution was withdrawn at suitable time interval was analyzed using UV spectrophotometer at $255 \mathrm{~nm}$.

Sterility test. ${ }^{12-14}$ Sterility testing is intended for detecting the presence of viable form of microorganisms and was performed by using fluid Thioglycolate medium and Soya bean casein digest medium, respectively as per the Indian Pharmacopoeia.

All the formulations were sterilized separately under UV radiation for 30mins.

The irradiated formulations were tested in aseptic conditions for viable forms of bacteria, fungi, Yeast in both the media prescribed by Indian Pharmacopoeia for 7 days.

Eye irritancy test. ${ }^{15,16}$ According to the Draize test, the ocular films were placed into the lower culde-sac with observation of the various criteria made at a designed time interval of $1 \mathrm{hr}, 24 \mathrm{hrs}, 48 \mathrm{hrs}, 72$ hrs and 1 week after administration. The male rabbits weighing 1.5 to $2 \mathrm{~kg}$ were used for the present study. Ethical clearance for the handling of experimental animals was obtained from the Institutional Animal Ethical Committee (IAEC) constituted for the purpose. The sterile formulation was instilled twice a day for a period of 7 days. Rabbits were observed periodically for redness, swelling, discharge, haemorrhaging, cloudiness, ulceration and blindness of the eye.

\section{RESULTS AND DISCUSSION}

Mechanical properties. Since the mechanical strength determines the suitability and acceptability of the ocular films, the Table 2 shows that as the hydrophilicity in the film increases the tensile strength decreases. As the plasticizer amount was same in all the formulations the elongation break and the strain shows moderate change with the increasing amount of hydrophilic polymers.

Folding endurance. The folding endurance was found to determine the ability of the film to rupture. It was found to be highest for F6 (29) and lowest for F1(22). It reveals that as the polymer concentration increases the folding endurance also increases (Table 3).

Uniformity of thickness. The mean thickness and the standard deviation of the insert were determined. The low standard deviation of all the nine formulations indicated uniform thickness of the prepared films. The thickness was found to be in the range of $0.14 \pm 0.01 \mathrm{~mm}$ to $0.15 \pm 0.01 \mathrm{~mm}$. The 
increase in thickness was found due to the increase in total polymer concentration (Table 3 ).

Weight of ocular insert. The weight of the insert was determined using digital balance. For all formulations the weight was found to be between $1.00 \pm 0.01 \mathrm{mg}$ and $1.08 \pm 0.01 \mathrm{mg}$ (Table 3).
\% Moisture absorption. The \% moisture absorption was calculated for all nine formulations in triplicate. According to the results obtained the moisture absorption was more in film containing PVP polymers due to its hydrophilic nature (Table 3 ).

Table 2. Mechanical properties of the prepared ocular films.

\begin{tabular}{cccc}
\hline $\begin{array}{c}\text { Mechanical } \\
\text { Properties }\end{array}$ & $\begin{array}{c}\text { Tensile Strength }\left(\mathrm{kg} / \mathrm{mm}^{2}\right) \\
\pm \mathrm{SD}\end{array}$ & $\begin{array}{c}\text { Elongation at break } \\
(\mathrm{mm} \%) \pm \mathrm{SD}\end{array}$ & Strain $\pm \mathrm{SD}$ \\
\hline F1 & $3.21 \pm 0.03$ & $36 \pm 0.01$ & $0.36 \pm 0.50$ \\
F2 & $2.11 \pm 0.01$ & $24 \pm 0.01$ & $0.24 \pm 0.04$ \\
F3 & $4.25 \pm 0.5$ & $30 \pm 0.08$ & $0.30 \pm 0.03$ \\
F4 & $1.69 \pm 0.02$ & $26.4 \pm 0.03$ & $0.26 \pm 0.20$ \\
F5 & $2.89 \pm 0.04$ & $40 \pm 0.02$ & $0.40 \pm 0.04$ \\
F6 & $1.89 \pm 0.30$ & $20 \pm 0.50$ & $0.20 \pm 0.04$ \\
F7 & $2.02 \pm 0.02$ & $26 \pm 0.04$ & $0.26 \pm 0.10$ \\
F8 & $3.25 \pm 0.01$ & $35.6 \pm 0.02$ & $0.35 \pm 0.06$ \\
F9 & $2.43 \pm 0.02$ & $39.2 \pm 0.01$ & $0.39 \pm 0.04$ \\
\hline
\end{tabular}

$\mathrm{SD}=$ Standard deviation and no of replicates $(\mathrm{n})=3$.

Table 3. Physico-chemical evaluation of the prepared ocular films.

\begin{tabular}{ccccccc}
\hline Formula & $\begin{array}{c}\text { Weight } \\
(\mathrm{mg}) \pm \mathrm{SD}\end{array}$ & $\begin{array}{c}\text { Thickness } \\
(\mathrm{mm}) \pm \mathrm{SD}\end{array}$ & $\begin{array}{c}\text { Folding } \\
\text { endurance }\end{array}$ & Surface $\mathrm{pH}$ & $\begin{array}{c}\text { Moisture uptake } \\
(\%) \pm \mathrm{SD}\end{array}$ & $\begin{array}{c}\text { Drug content }(\%) \\
\pm \mathrm{SD}\end{array}$ \\
\hline F1 & $1.05 \pm 0.01$ & $0.14 \pm 0.01$ & 22 & 7.2 & $1.57 \pm 0.06$ & $96.63 \pm 0.31$ \\
F2 & $1.02 \pm 0.01$ & $0.14 \pm 0.01$ & 26 & 7.2 & $2.44 \pm 0.02$ & $97.01 \pm 0.40$ \\
F3 & $1.02 \pm 0.01$ & $0.14 \pm 0.01$ & 27 & 7.3 & $1.36 \pm 0.32$ & $96.88 \pm 0.43$ \\
F4 & $1.08 \pm 0.01$ & $0.15 \pm 0.01$ & 27 & 7.2 & $5.47 \pm 0.36$ & $96.72 \pm 0.34$ \\
F5 & $1.00 \pm 0.01$ & $0.15 \pm 0.01$ & 26 & 7.3 & $4.58 \pm 0.27$ & $97.26 \pm 0.30$ \\
F6 & $1.01 \pm 0.01$ & $0.14 \pm 0.01$ & 29 & 7.2 & $4.29 \pm 0.09$ & $96.30 \pm 0.61$ \\
F7 & $1.07 \pm 0.01$ & $0.14 \pm 0.01$ & 25 & 7.3 & $4.28 \pm 0.07$ & $97.69 \pm 0.61$ \\
F8 & $1.06 \pm 0.01$ & $0.14 \pm 0.01$ & 23 & 7.2 & $1.15 \pm 0.23$ & $95.56 \pm 0.49$ \\
F9 & $1.06 \pm 0.04$ & $0.14 \pm 0.05$ & 28 & 7.3 & $3.27 \pm 0.19$ & $96.30 \pm 0.26$ \\
\hline
\end{tabular}

$\mathrm{SD}=$ Standard deviation and no of replicates $(\mathrm{n})=3$.

Surface pH. The surface $\mathrm{pH}$ for all the nine formulations was within the range of 7.2 to 7.3. Generally the $\mathrm{pH}$ of ophthalmic formulations should be within 4.5 to 11.5. As the drug of choice is basic, the $\mathrm{pH}$ of all the formulation showed in the range of 7.2 to 7.3 (Table 3 ).

Drug content uniformity. The drug content for all nine formulations was in the range of $96.3 \pm$ $0.61 \%$ to $97.69 \pm 0.61 \%$ of label claim. The IP specifications for assay of drug content should not be less than $90 \%$ and should not be more than $110 \%$ (Table 3).

Drug polymer interaction. The formulations and the pure drug were subjected to IR analysis. No major difference was observed in the spectra of pure
Valacyclovir Hydrochloride and with the formulations which indicates there was no chemical interaction between the drug and the other formulation ingredients (Figure 1).

In vitro drug release studies. All the formulations have been able to release the drug above $85 \%$ in $8 \mathrm{hrs}$ time. Among these few formulations like F1, F3, F8 showed comparatively lesser release (Figure 2) as it contains only one hydrophilic polymer. The effect of PVP in the formulations increased the release rate significantly. It was observed that as the proportion of PVP increased in combination with HPMC the release of drug became far better and showed release up to $98.51 \%$ in $8 \mathrm{hrs}$ time. Out of these nine formulations, F2 showed a 
release of $97.04 \%$, F4 showed a release of $98.51 \%$, F6 showed a release $97.62 \%$ at 8 hrs time (Figure 3).
The effect of hydrophilicity of the polymers resulted in high $\%$ of release in theses formulations.

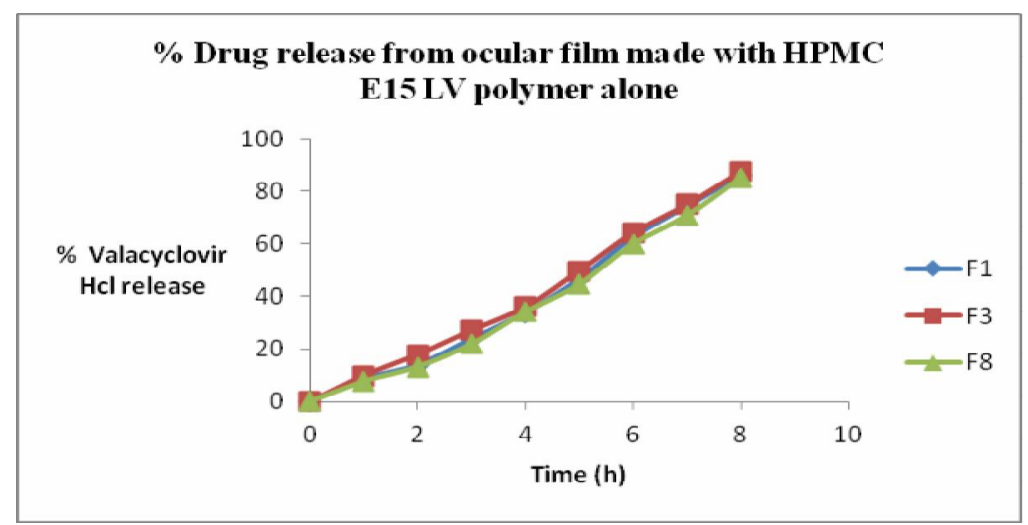

Figure 1. FTIR of valacyclovir hydrochloride with PVP and HPMC E5 LV

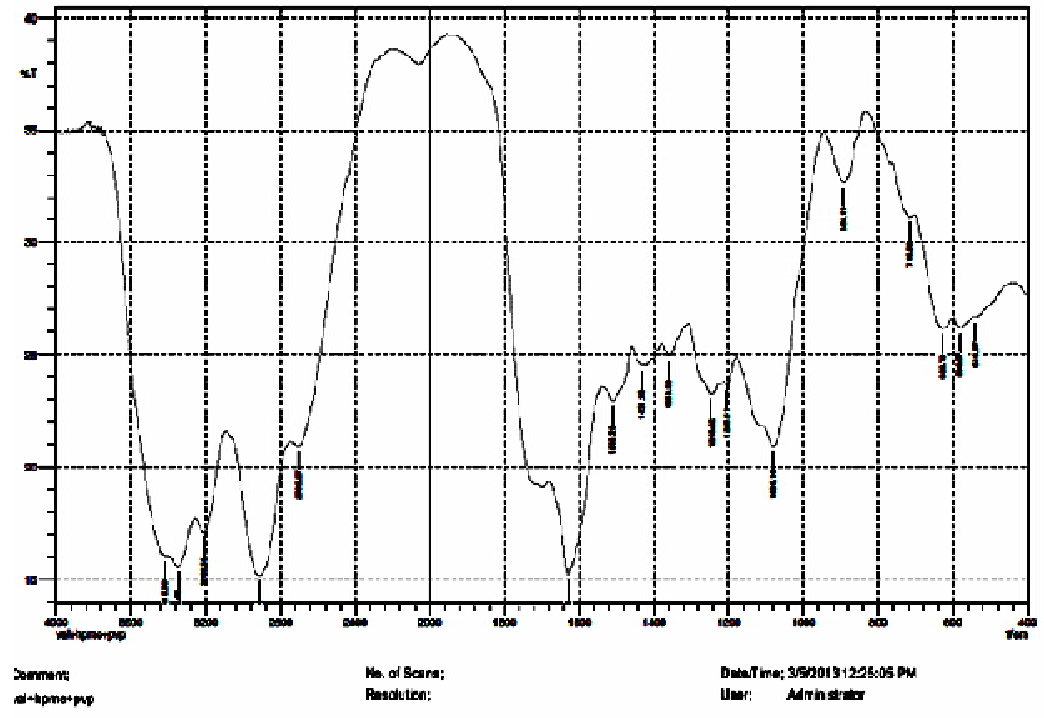

Figure 2. \% Release of valacyclovir $\mathrm{HCl}$ from the ocular film with HPMC E15 LV polymer

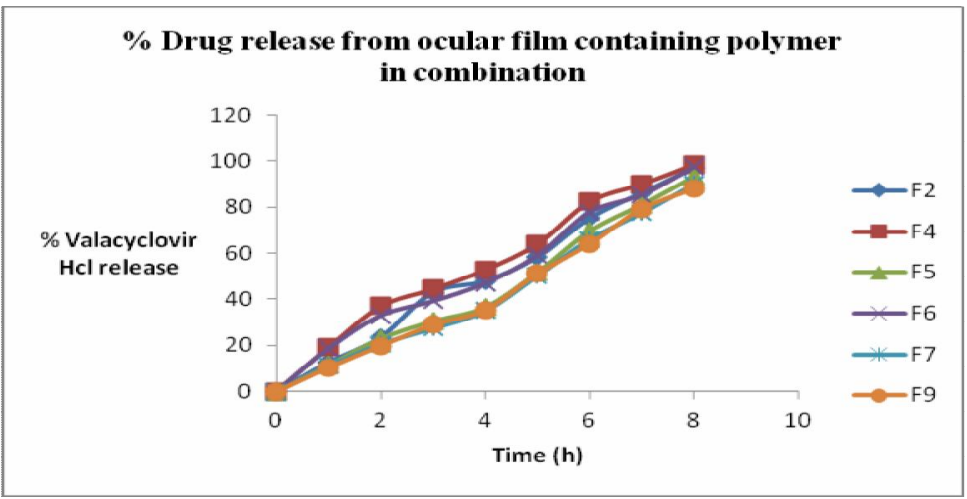

Figure 3. \% Release of valacyclovir $\mathrm{HCl}$ from the ocular film with HPMC E15 LV and PVP in combination at different ratios 
Mechanism and kinetics of drug release. The release data were subjected to kinetic analysis to show the mechanism of drug release from the ocular films which is presented in Table 4. The Korsemeyer Peppas model helped to determine the pattern of drug release from the polymer matrix. The model is described by the equation $\quad \mathrm{D} / \mathrm{D} \infty=\mathrm{K}_{\mathrm{KP}} \mathrm{t}^{\mathrm{n}}$ where $\mathrm{Dt} / \mathrm{D} \infty=$ fraction of drug release, $\mathrm{K}_{\mathrm{KP}}=$ Korsemeyer Peppas constant, $\mathrm{T}=$ time of release and $\mathrm{n}=$ diffusion exponent of drug release and has a value $0.5<n>1$. $n$ $=0.5$ indicates Fickian diffusion. $0.5<\mathrm{n}>1$ indicates
non-Fickian diffusion and Value of $\mathrm{n}>1$ indicates super case II transport.

Results of kinetics indicated that all values are greater than 0.5 and F1, F2, F3 and F8 have values greater than 1 which indicates super case II transport. Since, it is a soluble film, it is more amenable to follow anomalous diffusion i.e. involvement of diffusion mediated and polymer chain relaxation mediated drug release. The data indicates zero order from kinetic analysis as the $\mathrm{R}^{2}$ values are highest for the zero order.

Table 4. In-vitro release constant and regression values for different model.

\begin{tabular}{cccccccccc}
\hline $\begin{array}{c}\text { Formulation } \\
\text { code }\end{array}$ & $\mathrm{K}_{0}$ & $\mathrm{R}^{2}{ }_{0}$ & $\mathrm{~K}_{1}$ & $\mathrm{R}_{1}{ }_{1}$ & $\mathrm{~K}_{\mathrm{HG}}$ & $\mathrm{R}^{2}{ }_{\mathrm{HG}}$ & $\mathrm{K}_{\mathrm{KP}}$ & $\mathrm{R}^{2}{ }_{\mathrm{KP}}$ & $\mathrm{n}$ \\
\hline F1 & 15.1 & 0.97 & 0.33 & 0.96 & 34.67 & 0.78 & 2.89 & 0.99 & 1.32 \\
F2 & 18.4 & 0.99 & 0.27 & 0.90 & 43.07 & 0.88 & 2.03 & 0.98 & 1.01 \\
F3 & 15.63 & 0.99 & 0.30 & 0.95 & 36.13 & 0.81 & 2.51 & 0.99 & 1.1 \\
F4 & 19.63 & 0.97 & 0.21 & 0.92 & 46.48 & 0.93 & 1.60 & 0.98 & 0.73 \\
F5 & 16.76 & 0.99 & 0.28 & 0.95 & 38.84 & 0.82 & 2.09 & 0.99 & 0.85 \\
F6 & 18.63 & 0.98 & 0.22 & 0.95 & 43.87 & 0.90 & 1.64 & 0.98 & 0.66 \\
F7 & 16.08 & 0.98 & 0.29 & 0.96 & 37.18 & 0.81 & 2.27 & 0.96 & 0.94 \\
F8 & 14.63 & 0.97 & 0.33 & 0.96 & 33.54 & 0.77 & 2.98 & 0.99 & 1.37 \\
F9 & 16.01 & 0.99 & 0.29 & 0.95 & 37.04 & 0.82 & 2.33 & 0.98 & 0.99 \\
\hline
\end{tabular}

$\mathrm{K}_{0}=$ Zero order rate constant, $\mathrm{R}_{0}^{2}=$ Zero order Regression constant $\mathrm{K}_{1}=$ First order rate constant, $\mathrm{R}^{2}=$ = First order Regression constant $\mathrm{K}_{\mathrm{HG}}=$ Higuchi rate constant, $\mathrm{R}^{2}{ }_{\mathrm{HG}}=$ Higuchi Regression constant

$\mathrm{K}_{\mathrm{KP}}=$ Korsemeyer Peppas rate constant, $\mathrm{R}_{\mathrm{KP}}^{2}=$ Korsemeyer Peppas Regression constant, $\mathrm{n}=$ diffusion exponent of drug release

Sterility test. The sterile films complied with the test for sterility with a positive control and a negative control test as per the Pharmacopoeial procedure. The formulations also did not show any growth of microorganisms, which suggest that the films were sterile.

Eye irritancy test. There was no sign of redness, swelling, discharge, haemorrhaging, cloudiness, ulceration and blindness in the rabbit's eyes used for the study, indicating that ophthalmic films were free from ocular toxicity and safe for ocular use.

\section{CONCLUSION}

The erodible ocular films of Valacyclovir Hydrochloride can be prepared using different proportions of HPMC E $5 \mathrm{LV}$, and PVP as the polymers. All the prepared films showed the mechanical properties, and physico-chemical properties optimal to be used for eye. In the investigation the relative proportions of the individual polymers show some relationship with the two major evaluation parameters, namely, moisture uptake and drug release profile, both of which are similar processes dependent on the film matrix hydrophilicity and diffusivity of water in the films. There was not much difference in the folding endurance with respect to the change in polymers. But the moisture uptake varied exponentially with PVP, i.e., with increasing PVP content, the moisture uptake of the films increased exponentially, while with HPMC, with increasing HPMC content, the moisture uptake decreased exponentially. Since, exponential relation implies a first order process, it may be conjectured that the moisture uptake is occurring through slow diffusion process. The trend with respect to drug release at $8^{\text {th }}$ hour appears to be 
mediated by zero order kinetics and was increased with the increment of PVP content relating to matrix hydrophilicity. The films showed no ocular irritancy and toxicity when applied in rabbit eye and were considered as safe.

\section{ACKNOWLEDGEMENT}

We would like to express our gratitude and thanks to Cipla Pvt. Ltd. Mumbai for the gift sample of the pure drug valacyclovir hydrochloride.

\section{REFERENCES}

1. Imran, S., Banasal, A., Bushetti, S.S., Singh, A. and Chopra, H. 2009. Novel Ocular Dosage form in the treatment of Glaucoma. The Pharma Res. 1, 72-81.

2. Bondi, J.V., Harwood, R.J. 1988. Bio soluble ocular inserts. United States Patent 4,730,013.

3. Dias, C., Nashed, Y., Atluri, H. and Mitra, A. 2002. Ocular penetration of acyclovir and its peptide prodrugs Valacyclovir and val-valacyclovir following systemic administration in rabbits: An evaluation using ocular micro dialysis and LC-MS. Curr. Eye. Res. 25, 243-52.

4. Dhaliwal, D.K., Romanowski, E.G., Yates, K.A., Hu, D., Mah, F.S., Fish, D.N. and Gordon, Y.J. 2001. Valacyclovir inhibition of recovery of ocular herpes simplex virus type 1 after experimental reactivation by laser in situ keratomileusis. J. Cataract Refract. Surg. 27, 1288-93.

5. Gevariya, H.B., Patel, J.K., Girhepunje, K. and Pal, S.R. 2009. Sustained Ophthalmic Delivery of Levofloxacin from once a day Ocusert. Int. J. Pharm. Sci. 1, 24-32.
6. Sultana, Y., Aqil, M. and Ali, A. 2005. Ocular inserts for controlled delivery of pefloxacin mesylate: Preparation and evaluation. Acta Pharm. 55, 305.

7. Murthy, S.N. and Hiremath, S.R. 2002. Biodegradable polymers matrix based Ocuserts. Int. J. Pharm. Excip. 34-37.

8. Ubaidulla, U., Reddy, M.V. and Ruckmani, K. 2007. Transdermal therapeutic system of Carvedilol: Effect of hydrophilic and hydrophobic matrix on in vitro and in vivo characteristics. AAPS Pharm. Sci. Tech. 8, E1-E8.

9. Balasubramaniam, J., Srinatha, A., Pandit, J.K. and Gopalnath. 2006. In vitro microbiological evaluation of polyvinyl alcohol-based ocular inserts of ciprofloxacin hydrochloride. Indian J. Pharm. Sci. 68, 626-630.

10. Murthy, S.N. 1997. Biodegradable polymers matrix based Ocuserts of diclofenac sodium. Indian Drugs. 34, 336.

11. Dave, V., Paliwal, S. and Yadav, S. 2013. Formulation and evaluation of controlled delivery of Aceclofenac through ocular insert. Turk. J. Pharm. Sci. 10, 205-220.

12. Ministry of Health and Family Welfare, Government of India, New Delhi. 1996. Indian Pharmacopoeia 2, 117-47.

13. Dhanaraju, M.D., Sivakumar, V.R. and Bhaskar, K. 2002. Bioadhesive ocuserto matrix for ophthalmic administration of ciphofloxacin hydrochloride. Indian Drugs. 39, 222-224.

14. Patel, D.H., Patel, M.P. and Patel, M.M. 2009. Formulation and evaluation of drug-free ophthalmic films prepared by using various synthetic polymers. J. Young Pharmacists 1, 116-120.

15. Mohan, E.C., Jagan, M.K. and Venkatesham, A. 2009. Preparation and evaluation of in situ gels for ocular drug delivery. J. Pharm. Res. 2, 1089-94.

16. Draize, J., Woodward, G. and Calvery, O. 1994. Methods for the study of irritation and toxicity of substance applied topically to the skin and mucous membrane. J. Pharmacol. Exp. Ther. 82, 377-90. 